\title{
Relationship between knowledge and skill for basic life support in personnel of emergency medical services, Islamic Republic of Iran
}

\author{
Maryam Papi, ${ }^{1}$ Ashrafalsadat Hakim ${ }^{2}$ and Hadi Bahrami ${ }^{3}$
}

${ }^{1}$ Department of Nursing, Shoushtar Faculty of Medical Sciences, Shoushtar, Islamic Republic of Iran. ${ }^{2}$ Nursing Care Research Center in Chronic Diseases, Department of Nursing, Ahvaz Jundishapur University of Medical Sciences, Ahvaz, Islamic Republic of Iran. ${ }^{3}$ School of Nursing and Midwifery, Ahvaz Jundishapur University of Medical Sciences, Ahvaz, Islamic Republic of Iran. (Correspondence to: Ashrafalsadat Hakim: hakim344820o@yahoo. com)

\begin{abstract}
Background: Pre-hospital resuscitation in cardiac arrest is crucial to survival of patients, so emergency medical services personnel must have up-to-date knowledge and good skills.

Aims: This study aimed to determine the association between knowledge and skills of emergency medical services personnel of basic life support in north-west Khuzestan province, Islamic Republic of Iran.

Methods: This cross-sectional study included all personnel of emergency medical services (75 participants) in two emergency centres. Data were collected on characteristics of the participants (age, time since last retraining, academic degree, and length of experience), and their knowledge of basic life support. Skills were assessed by observing the personnel carry out basic life support and use of an automated external defibrillator on a mannequin.

Results: Poor knowledge was found in 31\% of the personnel (mean score: 19.35 (SD 3.9); range: 0-34) and 42.7\% had poor skills (mean score: 5.40 (SD 2.39); range: 0-9). Most of the staff (71\%) did not use the automated external defibrillator correctly. No statistically significant relationship was found between staff knowledge and skills $(P=0.298)$. Staff knowledge and skills were significantly associated with correct use of the defibrillator $(P=0.039)$. Knowledge score was significantly associated with length of time since doing resuscitation training $(P=0.006)$ and academic qualification $(P=0.046)$. The skills score was significantly associated with time since doing training $(P=0.004)$.
\end{abstract}

Conclusion: Strategies to maintain and improve the life support knowledge and skills of personnel in emergency medical services are recommended.

Keywords: heart arrest, resuscitation, emergency medical services, knowledge and skills, Iran

Citation: Papi M; Hakim A; Bahrami H. Relationship between knowledge and skill for basic life support in personnel of emergency medical services, Islamic Republic of Iran. East Mediterr Health J. 2020; 26(10): 1193-1199. https://doi.org/10.26719/emhj.19.018

Received: 06/05/18; accepted: 09/01/19

Copyright (c) World Health Organization (WHO) 2020. Open Access. Some rights reserved. This work is available under the CC BY-NC-SA 3.0 IGO license (https://creativecommons.org/licenses/by-nc-sa/3.o/igo)

\section{Introduction}

Cardiovascular diseases are the leading cause of death globally and cause one death every 12 minutes (1). In the Islamic Republic of Iran, $50 \%$ of all deaths each year and $79 \%$ of deaths related to chronic diseases are attributed to cardiovascular diseases (2). The first line of response to cardiac arrest is basic life support (3). This is a key component of the survival chain to reduce the death rate and increase the hospital discharge rate. Basic life support includes steps taken by skilled personnel during cardiac or respiratory arrest. It is a combination of artificial respiration and chest massage to restore cardiac function, blood circulation and respiration (4).

Survival from cardiac arrest is higher if handled in hospital $(22.3-25.5 \%)$ than in an out-of-hospital setting $(10.8 \%)$. One of the main reasons for this disparity is that rescuers often perform cardiopulmonary resuscitation (CPR) at suboptimal standards (5). Therefore, the skill of emergency medical personnel in resuscitation as the first line of assistance is an essential factor in the outcome of cardiac arrest (6). However, there is compelling evidence that emergency medical personnel lack the necessary skills in resuscitation (3). Moreover, recent studies show that some emergency medical personnel fail to perform accurate and rapid resuscitation operations; therefore, it is essential that they acquire the necessary skills and knowledge so they can respond effectively in a cardiac emergency (7).

Research suggests that with resuscitation outside the hospital, lack of adequate knowledge by emergency medical personnel has led to delayed medication and is one of the reasons for the failure of cardiopulmonary resuscitation (8). Other research indicated that $96 \%$ of emergency medical personnel had good knowledge of resuscitation, but their skills level was poor (9). To date, few studies have examined the relationship between basic life support knowledge and resuscitation skills in different groups of people (medical and non-medical). A study in 2016 found a positive correlation between knowledge and resuscitation skills (10), but another in 2014 found no relationship between the two variables (11). Given that most studies in the field of resuscitation are done in the hospital environment, this study aimed to determine the relationship between the knowledge 
of basic life support and skill in providing emergency medical services in pre-hospital resuscitation settings.

\section{Methods}

\section{Study design and sample}

This was a cross-sectional study to examine the relationship between the knowledge and skills of medical professionals in emergency medical services about basic life support. The study was conducted in two of four emergency centres in the north-west of Khuzestan province in 2016. The two sites were selected because of easier access and because they had more staff. All emergency medical personnel at these centres who met the inclusion criteria were included in the study. Inclusion criteria were emergency medical services personnel who had at least 6 months' experience; exclusion criteria were failure to fill out the questionnaire.

\section{Data collection}

Data were collected using two questionnaires in Farsi on: 1) demographic information (age, time of participation in retraining classes, academic degree and length of employment/work experience), 2) knowledge of basic life support.

After completing the questionnaires, the skills of the participants were assessed. For this purpose, a mannequin was placed in the room and each participant was asked to perform CPR on the assumption that it was a suspected cardiac arrest. Their skills were observed by two researchers. None of the participants declined to take part in this assessment. Because few staff had good resuscitation skills, emergency services authorities conducted a cardiopulmonary resuscitation workshop for all staff which was noted in the staff file.

The questionnaire measuring knowledge of resuscitation contained 34 questions on CPR, airway control, blood circulation control, the number of massages and breathing. A correct answer was scored as 1 , an incorrect answer was scored as 0 . A score of less than 17 indicated poor knowledge, between 17 and 25.5 indicated average knowledge, and scores higher than 25.5 indicated good knowledge.

Questionnaires were distributed by hand to participants and they were completed anonymously.

For CPR and automated external defibrillator skills testing, a checklist was used during observation of their basic life support skills and use of an automated external defibrillator. The checklist of America Heart Association was used; practices of the America Heart Association regarding resuscitation for cardiac arrest are taught by all main universities and colleges that provide training on emergency care, especially all forms of CPR (child and adult). All training centres for basic life support and advanced cardiac life support also use America Heart Association guidelines. Therefore, these guidelines were used to measure skills in our study. The steps include: checking consciousness level and response, Contacting emergency services(calling the emergency services number which is 115 in the Islamic Republic of Iran), checking carotid pulse, correct placement of hands for cardiac massage, first cycle of massage, giving two breaths, and use of automated external defibrillator and continuing CPR (second cycle of massage) respectively. For each step and procedure, we scored 1 for correct skill and zero for inadequate skill. Skill scores ranged between 0 and 9. A score less than 4.5 indicates poor skill, a score between 4.5 and 6.75 average skill and scores more than 6.75 good skill.

To determine the validity of the knowledge questionnaire and checklist, the questions were reviewed by 10 members of the faculty and emergency medical services personnel. The reliability of the checklist was assessed by 40 members of the staff and the Cronbach alpha was 0.86 .

\section{Statistical analysis}

Means and standard deviations (SDs), and frequencies were determined. The chi-squared test was used to assess the relationship between knowledge (poor, good) and skills (poor, average, good), and between knowledge and skills and skill in using the automated external defibrillator. Analysis of variance (ANOVA) was used to assess the relationship between academic qualification and level of knowledge, as the subgroups were normally distributed. The Kruskal-Wallis test was used to examine the relationship between knowledge and skill level and other characteristics of the participants which were not normally distributed. Because so few participants had good knowledge scores, we combined average and good knowledge into one category in the analysis.

Data were analysed using SPSS, version 22. $P<0.05$ was considered statistically significant.

\section{Ethical considerations}

The emergency centres are a subsystem of the cities' health network and university. Therefore, permission to carry out the study was obtained from the head of the health network and the study was coordinate with the emergency medical authorities. The purpose of the study was explained to the staff and they were assured of the confidentiality of their responses. Written informed consent was obtained from the participants.

\section{Results}

All eligible personnel (75 staff) agreed to participate (response rate $100 \%$ ). All the participants were males and most were in the age group $20-30$ years $(38,51 \%)$. Only 5 (7\%) participants were in the age group $41-51$ years. The mean age of the participants was 31.50 (SD 6.39) years. Of the 75 participants, $17(23 \%)$ were nurses, 35 (47\%) were emergency medical services personnel, and $23(31 \%)$ had academic qualifications not related to medicine. Most of the participants $(88 \%)$ had 1-10 years of experience and the remainder had between 11 and 21 years. Just over half $(41,55 \%)$ of the participants had done basic life support 
classes 12 months ago, 23 (31\%) had done them 6 months ago, and only 11 (15\%) had done them 3 months ago. Of the 11 participants who had done CPR classes 3 months ago, only one had a poor knowledge score, while almost half of the participants who had done CPR classes 12 months ago had a poor knowledge score.

The mean score of knowledge for basic resuscitation was 19.35 (SD 3.9) (range: 0-34) and the mean score for skills was 5.40 (SD 2.39) (range: 0-9), both of which are in the middle range. The knowledge level was poor for 23 (31\%) participants, average for $51(68 \%)$, and good for only 1 (1\%) participant. In addition, 32 (43\%) of the participants had poor skills, 21 (28\%) had average skills, and only 22 $(29 \%)$ had good skills. None of the participants obtained a full score for knowledge and only 6 (8\%) obtained a full score for skills.

Length of time since participating in basic life support training was the only variable significantly associated with the score in basic life support skills ( $P=$ $0.004)$ (Table 1). Time since participating in resuscitation training $(P=0.006)$ and academic qualification $(P=0.046)$ were significantly associated with the score in basic life support knowledge (Table 1). Of the 41 participants who had taken part in training classes 12 months ago, 21 had poor skills and only 7 had good skills. Of the 11 participants who had participated in training classes 3 months ago, 7 had excellent skills.

Table 2 shows that $71 \%$ of the staff did not use the automated external defibrillator correctly. There was a significant relationship between staff knowledge and skills and the correct use of the automated external defibrillator device $(P=0.039)$. No statistically significant relationship was found between staff knowledge and skills based on the chi-square test $(P=0.298)$ (Table 3$)$.

\section{Discussion}

Knowledge of basic CPR techniques and steps can increase the chance of survival of patients. Therefore, this study was conducted to determine the association between knowledge and skill of personnel of emergency medical services on CPR. Research in Nepal in 2012 showed that the mean score for resuscitation knowledge of medical/paramedical professionals was lower than average (12). Our study indicates that the knowledge (19.35, SD 3.9 ) and skill (5.40, SD 2.39) scores of basic resuscitation were average. Most of the participants $(68 \%)$ had an average knowledge score; only one had a good score. While more participants had good skills $(22,29 \%)$, a large proportion (43\%) had poor skills.

An Iranian study in 2007 reported that only $2.6 \%$ of nurses had good CPR knowledge, and none was classified as having a very good knowledge. However, if the number of people trained in CPR is higher in the community, then the survival rate and quality of life later will increase (13). Studies in Iraq (2014) and Japan (2003) found that most nurses had poor knowledge of CPR $(14,15)$, but in an Iranian study, the knowledge of most participants (85.6\%) was good and/or excellent; only $3 \%$ had poor knowledge (16). This difference could be because nurses with a

\begin{tabular}{|c|c|c|c|c|}
\hline Characteristic & $\begin{array}{c}\text { Basic life support knowledge } \\
\text { Mean (SD) }\end{array}$ & P-value & $\begin{array}{c}\text { Basic life support skills } \\
\text { Mean (SD) }\end{array}$ & P-value \\
\hline Age (years) & & $0.838^{a}$ & & $0.444^{\mathrm{a}}$ \\
\hline $20-30$ & $19.32(3.44)$ & & $5.57(1.95)$ & \\
\hline $31-40$ & $19.47(4.52)$ & & $4.78(2.91)$ & \\
\hline $41-51$ & $18.80(4.86)$ & & $4.60(1.51)$ & \\
\hline Job experience (years) & & $0.230^{\mathrm{a}}$ & & $0.411^{\mathrm{a}}$ \\
\hline $1-5$ & $18.37(3.63)$ & & $5.10(1.98)$ & \\
\hline $6-10$ & $20.25(3.75)$ & & $5.33(2.58)$ & \\
\hline $11-15$ & $19.25(6.89)$ & & $6.25(3.40)$ & \\
\hline $16-21$ & $18.80(4.86)$ & & $3.60(2.50)$ & \\
\hline Time of participating in retraining classes & & $0.006^{a}$ & & $0.004^{\mathrm{a}}$ \\
\hline 12 months ago & $18.49(4.03)$ & & $4.46(2.39)$ & \\
\hline 6 months ago & $19.39(3.75)$ & & $5.56(1.70)$ & \\
\hline 3 months ago & $22.45(2.73)$ & & $7.00(2.68)$ & \\
\hline Academic qualification & & $0.046^{\mathrm{b}}$ & & $0.056^{a}$ \\
\hline Nursing & $20.76(2.99)$ & & $5.17(2.03)$ & \\
\hline Emergency medical services & $20.43(5.12)$ & & $3.71(3.40)$ & \\
\hline Bachelor degree & $19.00(4.85)$ & & $3.40(3.09)$ & \\
\hline Associate degree & $22.17(2.22)$ & & $5.16(1.60)$ & \\
\hline Diploma & $18.06(3.78)$ & & $5.97(1.90)$ & \\
\hline
\end{tabular}




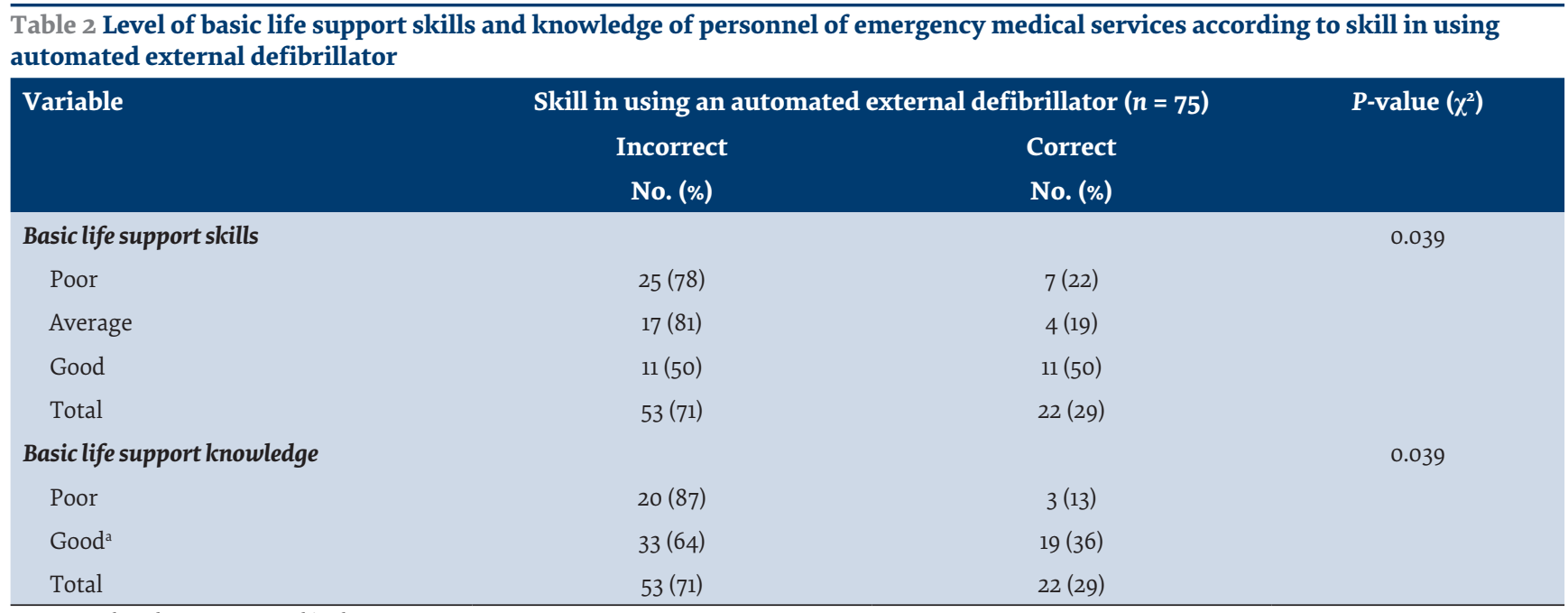

${ }^{a}$ Average and good groups were combined.

higher level of knowledge have more experience of CPR and resuscitation practice (17). In the Iranian study, most of the nurses worked in special units

With regard to demographic information, the Iraq study found no difference between the level of knowledge of basic resuscitation and age (14), which is consistent with our study. A study in Kerman province reported that length of employment had a positive effect on the knowledge level of nurses (18). In addition, a study in Saudi Arabia reported that participants with more than 10 years of experience has higher knowledge scores than those with less experience but the difference was not statistically significant (19). These findings suggest that staff with longer employment gain more experience in medical emergencies and this likely affects their knowledge. Most of our participants had a work experience of less than 5 years, and the authorities paid little attention to younger and less experienced nurses, who were not given much opportunity to participate in resuscitation or motivated to improve their level of knowledge, which may explain this finding. However, there is no statistically significant relationship between knowledge and length of employment (work experience) in our study results which concurs with the Iraq study (14).

Wefound a significantassociation between knowledge and academic qualification of staff; participants who had relevant degrees had greater knowledge of CPR. Of note is that $23(31 \%)$ of our participants had an academic qualification unrelated to the medical profession. This can affect the level of knowledge and skill of the participants and consequently affect the quality of resuscitation. In addition, training in resuscitation for those whose qualification is related to the medical profession is more effective because they have received such training in their curriculum (19). However, some studies have found no significant correlation between level of education and level of CPR awareness (16) and between field of study and knowledge and skill in basic CPR (20). This lack of difference may be because cardiopulmonary guidelines are designed for the public and anyone can learn CPR if they have enough motivation (21).

We found a significant association between knowledge and skills and the length of time since participating in classes on CPR, which is consistent with the findings of one Iranian study (16), but differs from the findings of another (22). Many studies have focused on the effect of participation in CPR classes on increasing knowledge among individuals. CPR training should be provided every 3 to 6 months to avoid deterioration in the knowledge and skill of all staff involved in the treatment of patients (6). Our results indicate that the shorter the interval between repeat training classes, the greater the resuscitation skills of participants.

In a study in 2014 in Kashan, more than two thirds of nursing students had a good skill level in use of an automated external defibrillator (23), while a 2006 study indicated that only $16.1 \%$ of participants could properly use the automated external defibrillator for resuscitation (4). The difference could explained because in the 2014

\begin{tabular}{|c|c|c|c|c|}
\hline \multirow{3}{*}{$\begin{array}{l}\text { Basic life support } \\
\text { knowledge }^{\mathrm{a}}\end{array}$} & \multicolumn{3}{|c|}{ Basic life support skills } & \multirow[t]{3}{*}{ P-value $\left(\chi^{2}\right)$} \\
\hline & Good & Average & Poor & \\
\hline & No. (\%) & No. (\%) & No. (\%) & \\
\hline Poor & $9(39)$ & $4(17)$ & $10(44)$ & \multirow[t]{2}{*}{0.298} \\
\hline Good & $13(25)$ & $17(33)$ & $22(42)$ & \\
\hline
\end{tabular}

${ }^{a}$ Average and good groups were combined. 
study, $63.5 \%$ of the participants had observed a real resuscitation between three and 10 times and $67.6 \%$ had participated in resuscitation. In our study, $29.3 \%$ of our participants had good skills in the use of an automated external defibrillator.

Low skills can endanger a patient's life. A study of 60 emergency technicians found their knowledge was moderate (24). Although accurate knowledge of CPR was associated with increased likelihood of correct performance of some aspects of CPR (compression rate, compression depth, compression to ventilation ratio), overall performance remained poor, which is not consistent with our study (24). This poor performance could be due to the quality of retraining classes and educational workshops and the interval between classes, as well as heavy work schedules, lack of motivation, lack of interest in the work, few encounters with medical emergencies, and not feeling a need to update CPR knowledge and not understanding its importance (9). In addition, in many cases when CPR is taught, feedback from participants on the training is not considered, but to improve knowledge and skill of CPR, both the training and a feedback system should be developed together.

We found no significant relationship between the knowledge of CPR of emergency medical services personnel and their skills in performing CPR. These results are similar to those obtained in a Korean study where there was no association between CPR skills and knowledge (11). By contrast, a positive correlation between knowledge and resuscitation skills was found in a Malaysian study. People who had a good knowledge of resuscitation had a high level of skill (10). This may be due to the fact that some employees with limited work experience still improve by observing the work of skilled staff. However, acquired skills may not reach the appropriate level because of substandard training. Furthermore, in some cases, new personnel have the necessary knowledge but will not be allowed to participate in the resuscitation operation by older more experienced staff. As a result, they do not acquire the necessary skill.

A limitation of our study was that the sample size was small and only two emergency medical centres were included. It is suggested that similar studies be done with larger samples of personnel from emergency medical services.

\section{Conclusions}

The findings of the research indicate that the knowledge and skill of emergency medical services personnel are average. However, none of the participants obtained a full score of knowledge and only six obtained a full score of skills. Considering the importance of basic resuscitation in the pre-hospital environment, updating the knowledge and skills on resuscitation is essential and should be mandatory for all treating staff (nurses and doctors). Therefore, more attention to maintaining and improving the CPR knowledge and skills of personnel in emergency medical services is recommended. This can be done through high-quality training classes, annual revalidation of resuscitation skills and enhancing motivation. Recruitment of personnel with relevant academic qualifications is also suggested.

\section{Acknowledgement}

We thank the emergency nursing staff who generously assisted in the implementation of this study.

Funding: None.

Competing interests: None declared.

\section{Relation entre savoir et savoir-faire pour les soins de base en réanimation chez le personnel des services médicaux d'urgence en République islamique d'Iran}

\section{Résumé}

Contexte : La réanimation préhospitalière en cas d'arrêt cardiaque est cruciale pour la survie des patients ; le personnel des services médicaux d'urgence doit donc être à jour au niveau de ses connaissances et son savoir-faire dans ce domaine.

Objectifs : La présente étude visait à déterminer l'association entre connaissances et savoir-faire chez le personnel des services médicaux d'urgence en ce qui concerne la réanimation cardio-respiratoire, dans la province du Khuzestan du nord-ouest, en République islamique d'Iran.

Méthodes: Cette étude transversale a impliqué l'ensemble du personnel des services médicaux d'urgence (75 participants) de deux centres d'urgence. Les données recueillies portaient sur les caractéristiques des participants (l'âge, date de la dernière formation, diplôme, et années d'expérience) et sur leurs connaissances en réanimation cardio-respiratoire. Les compétences ont été évaluées en observant le personnel effectuer une réanimation sur un mannequin à l'aide d'un défibrillateur externe automatisé. 
Résultats: Un niveau de connaissance faible a été observé chez $31 \%$ du personnel (score moyen: 19,35 (ET 3,9) ; fourchette comprise entre 0 et 34 ) et $42,7 \%$ avaient un niveau de savoir-faire faible (score moyen : 5,40 (ET 2,39) ; fourchette comprise entre 0 et 9). La plupart du personnel (71\%) n'a pas utilisé correctement le défibrillateur externe automatisé. Aucun rapport statistiquement significatif n'a été observé entre les connaissances et le savoir-faire du personnel ( $p=0,298)$. Les connaissances et le savoir-faire du personnel avaient un lien significatif avec l'utilisation correcte du défibrillateur $(p=0,039)$. Le niveau de connaissances avait un lien significatif avec le temps passé depuis la formation en réanimation $(p=0,006)$ et le diplôme universitaire $(p=0,046)$. Le niveau de savoir-faire avait une corrélation significative avec le temps passé depuis la dernière formation $(p=0,004)$.

Conclusions : Il est recommandé d'appliquer des stratégies de maintien et d'amélioration des connaissances et du savoir-faire du personnel des services médicaux d'urgence en terme de réanimation cardio-respiratoire.

$$
\begin{aligned}
& \text { العلاقة بين المعلومات والمهارات اللازمة للدعم الأساسي للحياة لدى العاملين في الخدمات الطبية في حالات }
\end{aligned}
$$

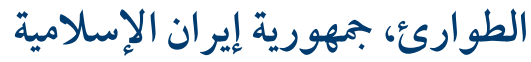

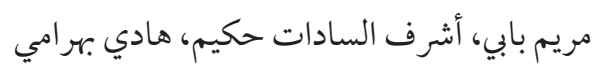

$$
\begin{aligned}
& \text { الخلاصة }
\end{aligned}
$$

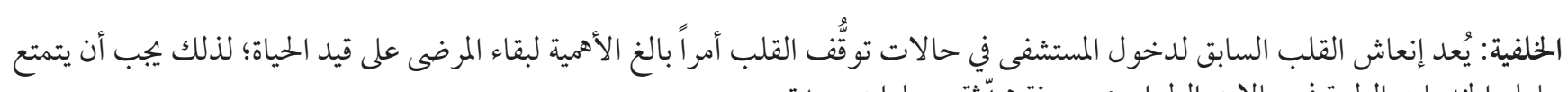

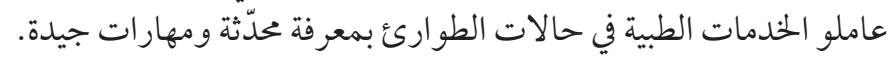

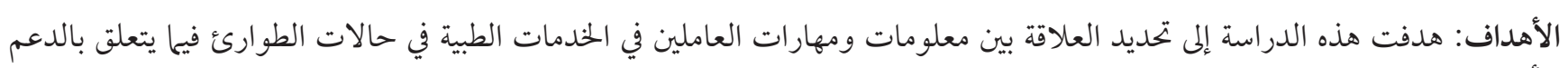

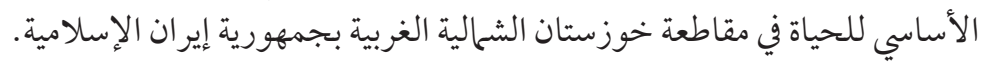

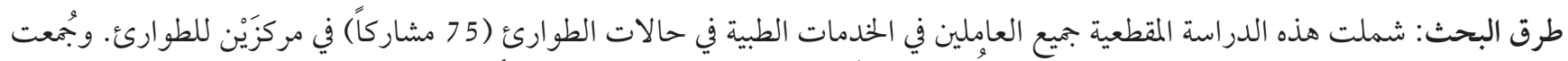

$$
\begin{aligned}
& \text { على مانيكان. }
\end{aligned}
$$

\section{References}

1. Cardiovascular disease: Australian facts 2011. Canberra: Australian Institute of Health and Welfare; 2011 (https://www.aihw.gov. au/getmedia/13cdo81b-8123-4660-ad68-3d780c12ffeb/12116-20111005.pdf.aspx, accessed 20 August 2019).

2. Sadeghi M, Haghdoost AA, Bahrampour A, Dehghani M. Modeling the burden of cardiovascular diseases in Iran from 2005 to 2025: the impact of demographic changes. Iran J Public Health. 2017;46(4):506-16.

3. Nori JM, Saghafinia M, Motamedi MHK, Hosseini SMK. CPR training for nurses: how often is it necessary? Iran Red Crescent Med J. 2012;14(2):104-07.

4. Saghizadeh M, Rahmani A, Ahangharzadeh Rezaie S. [Investigation of nurse's knowledge and practice working in CCU wards of Taleghani Hospital of Urmia University of Medical Sciences regarding adult CPR]. J Urmia Nurs Midwifery Fac. 2006;4(3):99103. (In Farsi)

5. Veronese J-P, Wallis L, Allgaier R, Botha R. Cardiopulmonary resuscitation by emergency medical services in South Africa: barriers to achieving high-quality performance. Afr J Emerg Med. 2018;8(1):6-11. https://doi.org/10.1016/j.afjem.2017.08.005

6. Rajeswaran L, Ehlers VJ. Cardiopulmonary resuscitation knowledge and skills of registered nurses in Botswana. Curationis. 2014;37(1):1-7. https://doi.org/10.4102/curationis.v37i1.1259 
7. Seidabady M, Mohammadi R, Mohammadi Y, Abumaash Zadeh S, Mohammadi A. [Evaluation study of skills and knowledge about the basic cardiopulmonary resuscitation (CPR) life supports among bachelor freshman emergency medical students in 2014]. J Clin Res Paramed Sci. 2015;4(2):102-11. (In Farsi)

8. Brown TB, Dias JA, Saini D, Shah RC, Cofield SS, Terndrup TE, et al. Relationship between knowledge of cardiopulmonary resuscitation guidelines and performance. Resuscitation. 2006;69(2):253-61. https://doi.org/10.1016/j.resuscitation.2005.08.019

9. Aroor AR, Saya RP, Attar NR, Saya GK, Ravinanthanan M. Awareness about basic life support and emergency medical services and its associated factors among students in a tertiary care hospital in South India. J Emerg Trauma Shock. 2014;7(3):166-9. https://doi.org/10.4103/0974-2700.136857

10. Cheah P, Chin S, Seow S. Skill retention after basic life support training in health care providers and laypersons; a pilot study. Poster presented at the 16th International Conference on Emergency Medicine (ICEM), 18-21 April, 2016, Cape Town, South Africa (https://doi.org/10.7490/f10ooresearch.1112326.1, accessed 20 October 2019).

11. Roh YS, Issenberg SB. Association of cardiopulmonary resuscitation psychomotor skills with knowledge and self-efficacy in nursing students. Int J Nurs Pract. 2014;20(6):674-9. https://doi.org/10.1111/ijn.12212

12. Roshana S, Kh B, Rm P, Mw S. Basic life support: knowledge and attitude of medical/paramedical professionals. World J Emerg Med. 2012;3(2):141-5. https://doi.org/10.5847/wjem.j.issn.1920-8642.2012.02.011.

13. Khoshrang H, Heidarzadeh A, Asadi A. [Assessment of the effects of education in clinical skills center on cardiopulmonary resuscitation knowledge of physicians and nurses working in educational therapeutic centers of Guilan University of Medical Sciences in 2004]. Res Med Educ. 2007;9:7-13. (In Farsi)

14. Mustafa MAK. Assessment of nurses' knowledge towards cardiopulmonary resuscitation at Al-Najaf City's teaching hospital. Kufa J Nurs Sci. 2014;4(1):1-10.

15. Nagashima K, Takahata O, Fujimoto K, Suzuki A, Iwasaki H. [Investigation on nurses' knowledge of and experience in cardiopulmonary resuscitation and on nurses' knowledge of the guidelines for cardiopulmonary resuscitation and emergency cardiovascular care established in 2000-results of a survey at Asahikawa Medical College Hospital (second report)]. Masui. 2003;52(4):427-30. [In Japanese]

16. Pourmirza Kalhori R, Saboor B, Naderi Pour A, Almasi A, Godarzi A, Mirzaee M. Survey of the awareness level of nurses about last guidelines of cardiopulmonary resuscitation (CPR) in educational hospitals. Iran J Crit Care Nurs. 2012;5(2):77-86.

17. Passali C, Pantazopoulos I, Dontas I, Patsaki A, Barouxis D, Troupis G, et al. Evaluation of nurses' and doctors' knowledge of basic and advanced life support resuscitation guidelines. Nurse Educ Pract. 2011;11(6):365-9. https://doi.org/10.1016/j.nepr.2011.03.010

18. Mohsenpour M, Imani Z, Abdolkarimi M. [The effect of education of cardiopulmonary resuscitation (CPR) on knowledge of nursing staff and CPR team members in a hospital in Kerman province]. J Qual Res Health Sci. 2010;9(1\&2):1-7. (In Farsi)

19. Alotaibi O, Alamri F, Almufleh L, Alsougi W. Basic life support: knowledge and attitude among dental students and staff in the College of Dentistry, King Saud University. Saudi J Dent Res. 2016;7(1):51-6. https://doi.org/10.1016/j.sjdr.2015.06.001

20. Davari F, Khanjari S, Assemi S, Haghani H. [Basic cardiopulmonary resuscitation training and its effect on knowledge and skill level of high school students]. Iran J Nurs. 2004;17(39):57-63. (In Farsi)

21. Saffari M, Amini N, Pakpour AH, Sanaeinasab H, Jahan HR. [Assessment the medical sciences students' knowledge and skill about basic cardiopulmonary resuscitation (CPR) in accidents and disasters]. Iran J Health Educ Health Promot. 2013;1(1):41-50. (In Farsi)

22. Borimnejad L, Nikbakht Nasrabadi A, Mohammadi Mohammadi H. [The effect of cardiopulmonary resuscitation workshop on nurses' sustained learning]. Iran J Med Educ. 2008;7(2):209-15. (In Farsi)

23. Adib-Hajbaghery M, Lotfi MS. Longitudinally investigation of the skills of cardiopulmonary resuscitation in nurse interns of Kashan University of Medical Sciences. Iran J Cardiovasc Nurs. 2014;3(1):6-17. (In Farsi)

24. Brown TB, Dias JA, Saini D, Shah RC, Cofield SS, Terndrup TE, et al. Relationship between knowledge of cardiopulmonary resuscitation guidelines and performance. Resuscitation. 2006;69(2):253-61. https://doi.org/10.1016/j.resuscitation.2005.08.019 